\title{
The Perky effect: Changes in reality judgments with changing methods of inquiry'
}

\author{
SYDNEY JOELSON SEGAL, Center for Research in Cognition \\ and Affect. New York, N.Y. 10036
}

When Ss were asked to describe their imagery of common items, and a stimulus was present during one image, 31 of 32 Ss did not realize that anything was projected. With a forced-choice inquiry, Ss scored slightly above chance, especially with a brighter signal, however, information concerning the true appearance of the signal caused a decline in accuracy. On a final task, Ss discriminated the same signal correctly on $98 \%$ of the trials.

If perception depends on a central executive which integrates afferent expectancies and efferent signals, and if an image is also a construction, dependent on central integration, how can they be differentiated? This new view of perception and imagery, forcefully enunciated by Neisser (1966) and also maintained, although less radically, by Gregory (1966), and Attneave (1962) among others, re-awakens interest in Perky's old demonstration (1910). Perky asked observers to imagine specific items; during their imagery, a dim but supraliminal facsimile of the item was placed on a screen directly in their line of regard. Her observers described images which sometimes resembled the stimuli, but they uniformly failed to identify the stimuli as "real." When Perky's paper was written, she was not able to give a meaningful theoretical interpretation; today, however, such an interpretation is possible. If we conclude, with Swets (1961), that there is no absolute sensory threshold, then it is not surprising that a stimulus may be judged as "real" under one condition, "imaginary" in another. However, if both the image and the perception are a construction, and if experienced vividness is not a reliable index of "reality" (cf., Neisser, p. 150), then how does a person make the discrimination? What is the basis of reality testing?

It is here assumed that reality testing is a decision, based on probabilities; that given a specified constructed experience, $S$ makes a decision about the source of the experience according to the weighting of probabilities. Perky's phenomenon is a useful paradigm for studying this decision process; and in the present study, her phenomenon will be explored under conditions designed to examine this decision process as changing conditions of inquiry shift the probabilities.

In Perky's original study, 27 Ss each experienced six images: after recording all introspections, the experimenter asked the Ss "if they were quite sure they had imagined all those things." This question "almost always aroused surprise and at times indignation" (p. 431). In the author's early experiments (Segal \& Nathan. 1964), a more careful inquiry was used; but it also occurred after all descriptions of imagery had been reported and recorded, so we had to rely on Ss' memory of 20 to $40 \mathrm{~min}$ old events rather than on their immediate decision. In a later experiment (Segal. 1968) Ss were told that stimuli might be shown. and asked. after each image, if a signal had been present. With memory thus controlled for. Perky's effect was still present. although much weaker. But in this study, the variable of information was also controlled. as all Ss knew a stimulus might be shown.

However, Perky's effect was characterized by the use of an unknown signal and Ss who expected to experience imagery. In the present study, these characteristics will be retained. but without burdening the memory. This is achieved by giving each $\mathrm{S}$ a single experience and demanding an immediate judgment.

\section{METHOD}

Thirty-two undergraduate students at the City University of New York, 16 males. 16 females. ages 17-24. served as paid volunteer Ss. Each $S$ was told that iniagery is a common sxperience, used when trying to recall a place or person. Then he was seated in a chair. with his head in a cone-shaped vinyl hood. so he regarded a small screen placed at the apex. He was then given what was called a "practice" session, where he was asked to imagine and describe his images of four objects: a banana, a parrot, a plant, and a violin. The banana and parrot were truly practice items; but a stimulus was projected onto the screen during the image of either the plant or the violin.

Immediately following the image of the violin, $S$ was asked the following questions:

(1) Was anything external put onto the screen during your images?

(2) During the last image, the image of a violin, was there any thing external on the screen?

(3) During the third image, the image of a plant, was there anything external?

(4) Now I will tell you: something was placed on the screen during either your third or your fourth image. I want you to guess which it was: accompanying the third image, the plant; or the fourth image, the violin? (Why did you guess that one?)

(5) Let me tell you further: a geometric shape of two incomplete red squares was projected onto the screen. Please guess again on which image it occurred. You may guess the same as in Question 4, or differently if this information makes you change your mind.

The stimulus that was projected was a red outline of two incomplete squares. The larger one lacked a bottom line; the smaller one was placed on top of it and was incomplete on the right side. It roughly resembled a table with a hook on top. This slide was projected from an adjacent room through a large window onto the screen of the hood. Before the $S$ was seated under the translucent hood, the projection room was dark and the projector was hidden.

For half the Ss, the figure was shown for $2 \mathrm{sec}$, at a brightness of $8.75 \mathrm{ft}-\mathrm{c}$ compared to about 8.5 for the background. For the other half, brightness was gradually increased from background to $8.75 \mathrm{ft}-\mathrm{c}$, then dimmed, over a total of $6 \mathrm{sec}$.

Immediately following the inquiry, Ss were returned to the hood, and presented the same stimulus for simple discrimination. There were five discrimination trials, three with the stimulus present, two without the stimulus.

\section{RESULTS AND DISCUSSION}

After experiencing the images, $S$ answered five questions, which can be construed as three judgments: the first three questions are his immediate uninstructed impression; the fourth question is a forced-choice after $\mathbf{S}$ was informed that a stimulus was present on one image; the fifth question is a forced-choice with more information concerning the appearance of the stimulus. Finally, $S$ was given a further experience with the stimulus, in which he was looking for a signal, and had to discriminate the signal from no signal on five trials.

Table 1 shows these data. There seemed to be a slight difference between the gradually brightening and the $2-\mathrm{sec}$ signal. The

Table 1

Per Cent Correct Discriminations with Different Inquiry Techniques

\begin{tabular}{lcccc} 
& $\begin{array}{c}\text { Questions } \\
1: 3\end{array}$ & $\begin{array}{c}\text { Question } \\
4\end{array}$ & $\begin{array}{c}\text { Question } \\
5\end{array}$ & Discrimination \\
\hline $\begin{array}{l}\text { Gradual onset } \\
\text { 6-sec stimulus }\end{array}$ & $6.25 \%$ & $75 \%$ & $56.25 \%$ & $100 \%$ \\
$\mathrm{~N}=16$ & & $50 \%$ & $37.5 \%$ & $96 \%$ \\
$\begin{array}{l}\text { 2-sec stimulus } \\
\mathrm{N}=16\end{array}$ & $0 \%$ & & & \\
\hline
\end{tabular}

$\%$ correct

discriminations

combined

$3: \quad 62.5 \% \quad 47 \%$

$47 \%$

$98 \%$

$N=32$ 
gradually brightening one was identified by one $\mathrm{S}$ during the first three questions; 12 of the 16 Ss could identify it with the forced-choice technique $\left(x^{2}=4.00, p<.05\right)$; only nine in the second forced-choice; but all 16 identified it perfectly in the discrimination trials. With the $2-\sec$ stimulus, no $S$ identified it after the imaging task, all scored at chance level in the forced-choice questions, and 3 made errors in the discrimination task. While these differences are not significant, they suggest that with the 6-sec signal, which was shown elsewhere (Segal, 1968) to have a greater total brightness, the probability of $\mathrm{S}$ guessing correctly is greater.

When all the data are combined, it appears that there was practially no correct identification of the stimulus in the three questions which followed imaging. However, in the discrimination task, with a new set of probabilities, Ss were correct in detecting the same stimulus $98 \%$ of the time. Thus, with an immediate inquiry, but with Ss expecting imagery and uninformed about the possible presence of a stimulus, the Perky effect seems replicable. A stimulus which was correctly detected on $98 \%$ of the discrimination trials was detected by only one of the 32 Ss $(3 \%)$ in the Perky task. The difference is significant at $p<.001$ by $\chi^{2}$ or any other statistical test.

More interesting is the comparison of the two forced-choice questions. On Question 4, Ss did slightly better than chance: by $x^{2}$ analysis, such a difference would be obtained by chance about one in 10 times. When asked why they made the guess they did, Ss seemed to have a sense of what was "their own." They would report: "before the image of a plant that I reported, I imagined a pot of geraniums-I think that was projected" or "I had to think hard to imagine the plant; but the violin was just there" or "the image I had of the plant was funny, so I think it was projected." None of them, however, could identify the stimulus that was projected; many assumed that it was the plant or the violin that was projected.

When Ss were informed about the form actually projected, most persisted in their original judgment. Only five changed, all from a correct to an incorrect guess. That is, information concerning the "true" physical appearance of the stimulus did not improve Ss' judgment, but actually interfered. When asked to imagine an object, S may draw on internal representations and weak uncoded external stimuli to construct the image. With forced-choice inquiry, he may be able to report a vague impression of an external source. However, since the signal was apprehended only in part and assimilated to the constructed image, information concerning its "true" appearance can only be misleading.
When the Perky effect is viewed this way. it appears transformed into two contemporary issues. One is the effect of attitude on detection: while $S$ is evaluating dim signals. concurrent mental activity may interfere with signal detection. This has been demonstrated in many vigilance problems: it is most clearly shown in the work of Kahneman. Beatty. \& Pollack (1967). who found the pupils were dilated during imaging. and detection was poorer. In addition. the expectancies and information $S$ brings to a task largely influence his judgment (cf., Bruner. 1957).

The second problem is the way unattended material is taken up: papers on subliminal or incidental perception (Fisher \& Paul. 1959: Pine. 1960) show how this material is apprehended in fragmented form. and integrated only in terms of stable drive tendencies of the organism or the current focal task. In the present experiment. partially coded material could lead to a slight improvement in S's reality judgment; but once it was taken into the focal task, it could no longer be coded in terms of its "true" physical appearance.

\section{REFERENCES}

ATTNEAVE, F. Perception and related areas. In S. Koch (Ed.), Psychology: A study of a science. New York: McGraw-Hill, 1962. Pp. 619-659.

BRUNER, J. S. On perceptual readiness. Psychological Review, 1957, 64, 123-152.

FISHER, C., \& PAUL, 1. H. The effect of subliminal visual stimulation on images and dreams: $A$ validation study. Journal of the American Psychoanalytic Association, 1959, 7, 35-83.

GREGORY, R L. Eye and brain. New York: McGraw-Hill, 1966.

KAHNEMAN, D., BEATTY, J., \& POLLACK, I. Perceptual deficit during a mental task. Science, 1967, 157, 218-219.

NEISSER, U. Cognitive psychology. New York: Appleton-Century-Crofts, 1967.

PERKY, C. W. An experimental study of imagination. American Journal of Psychology, 1910, 21, 422-452.

PINE, F. Incidental stimulation: a study of preconscious transformation. Journal of Abnormal \& Social Psychology, 1960, 60, 68-75.

SEGAL, S. J. The effect of imaging on the detection of an ambiguous visual signal. AFOSR Report No. OSR-68-1622, July, 1968.

SEGAL, S. J., \& NATHAN, S. The Perky effect: incorporation of an external stimulus into an imagery experience under placebo and control conditions. Perceptual \& Motor Skills, 1964, 18, 385-395.

SWETS, J. A. Is there a sensory threshold? Science, 1961, 134, 168-177. NOTE

1. This work was supported by AFOSR Contract F44620-68-C0013 to S. Segal. My thanks to Dr. Jerome L. Singer, for his critical comments on the paper, and to Vincent Fusella, who assisted in carrying out the experiment. 